\title{
Research in information sciences: An African perspective. Edited by L.O. Aina. Gaborone: University of Botswana, 2002. 220p.
} ISBN 978-032-053-9

The publication of this book is a significant contribution to the field of Library and Information Research, largely because of the lack of relevant textbooks on this subject at the tertiary level. The book consists of contributions from well-known LIS researchers in Africa, six of whom are based at the University of Botswana. All nine chapters are well-written, clearly setting out basic LIS research concepts, though with examples that have an African flavour.

The first chapter, Introduction to research, is by Lenrie Aina. It describes concepts basic to research, such as terminology, characteristics, typology, and the research process. Specific aspects covered are setting out the research problem, identifying the objective(s) of the research, posing the research question and formulating a hypothesis in order to find a solution to the research problem. It also discusses how to undertake a literature review, how to set the research methodology and how to report on the results of the research, aspects that are fundamental for LIS students at the introductory stage of research in tertiary education. The illustrations used in the chapter makes the presentation highly comprehensible and readable.

The next chapter, Research methodologies in information science, is by Aina together with Ajiferuke, who is a senior lecturer in Information and Media Studies at the University of Western Ontario, Canada. This chapter is an extension of the overview of the research methodologies given in Chapter One. Research design, methods, instruments, sampling, etc commonly used in LIS research, are discussed clearly and precisely. In Chapter Three, the late Richard Onyango looks at Data collection instruments in information science in his inimitable way. He examines the main LIS research instruments, such as questionnaires, interviews, observation and documentary sources, and concludes by considering on the problems of data collection instruments with reference to the African situation.

Chapter Four by B.C. Serema and Patricia Mooko focuses on the critical component, namely Information resources in Library and Information Science research.

The use of archival sources for research is not common in LIS research. In Chapter Five, Nathan Mnjama discusses Using archival sources for research in Africa by providing an account of the state of archival development in Africa; highlighting the nature of archival sources, the value of archives, methods of archival arrangement, retrieval, and problems of using archival materials in Africa. This chapter is particularly relevant for the African situation.

Chapter Six on Use of statistics in Library and Information Science research by I.S.Y. Ajiferuke examines a component of LIS research that is rarely understood by beginning researchers, and even some senior LIS researchers. He highlights the main aspects of descriptive and inferential statistics applicable in LIS research, in a style that will be easily understood by students at all levels.

Computers continue to support research in numerous ways, particularly in the processing, analysis and retrieval of research information. In Chapter Seven, Kgomotso Moahi makes a unique presentation of Computer applications in Library and Information Science research including a rich description of electronic and digital sources, as well as virtual libraries and web-based searching facilities (i.e. search tools and search engines) and methods.

Chapter Eight, General issues in research by Aina offers a blend of useful information that a researcher should consider carefully when reporting research.

The final chapter discusses Writing a Research Proposal in the Information Sciences. Amos Thapisa provides helpful points on the essentials to be included in the research proposal. A research proposal is of course fundamental to every research activity.

It is important to note that Research in Information Sciences. An African Perspective is couched as a textbook for LIS research beginners. Each chapter in the book ends with helpful review questions for self-learning and self-assessment. Although the list of references provided at the end of each chapter will not necessarily be new or current to all readers, some references will be useful for LIS researchers to pursue so as to supplement and extend what is covered by this book. Since research concepts, processes and practices are pretty much universal, those who expect a consistently African orientation are likely to be disappointed. Roughly $70 \%$ of the content reflects widely known information. Nevertheless, an African perspective is given attention in a few chapters. On the whole, the information provided in the 
book is accurate. Although the book is a compilation by several authors, each with a unique syntactic and semantic style and presentation, this individuality has not interfered with the quality of the presentations; rather has enriched it.

This book is a good introduction to LIS research for students beginning their studies, and may also be used by senior researchers, if supplemented by other research sources in the humanities and social sciences. This reviewer recommends the book to individuals and libraries of higher education institutions, particularly in Africa, provided it is affordable, wellmarketed and readily available. The writers of this book should be commended for their contribution to the need for an African textbook.

Dennis N Ocholla, Department of Library and Information Science, University of Zululand, South Africa e-mail: docholla@pan.uzulu.ac.za 